\title{
Salience of similarity awareness and attraction: A comparison of balance vs reinforcement predictions
}

\author{
CLYDE HENDRICK* and B. A. SEYFRIED \\ Kent State University, Kent, Ohio 44242
}

\begin{abstract}
Reinforcement and balance theory are both viable explanatory contenders for attraction processes. Differential predictions were derived and tested. Ss rated their attraction toward five strangers who were $.00, .25, .50, .75$, or 1.00 similar in attitudes. Half of the Ss rated perceived similarity to the strangers prior to making the attraction ratings (similarity/then liking condition) and the other half rated attraction prior to similarity ratings (liking/then similarity condition). Balance theory would predict an interaction between order of rating conditions and proportion of similar attitudes in determining attraction. Results showed that the only significant effect was due to proportion of similar attitudes. Factor analyses of the rating data showed that attraction and similarity ratings loaded on different factors. This result indicates that perceived similarity does not necessarily mediate attraction. Trend analyses suggested that the reverse may hold to some extent; perception of attraction may partially determine perceived similarity. This result suggests that a restricted balance model may be viable. However, the preponderance of the evidence supported reinforcement theory.
\end{abstract}

Byrne (1971) has presented impressive documentation that attraction is a positive (and generally) linear function of similarity on a wide variety of stimulus attributes. Further, the search for conditions that yield a reversal of the positive similarity-attraction relation has met with only occasional success (e.g., Hendrick \& Brown, 1971). The relation may be interpreted in terms of a cognitive theoretical orientation emphasizing the informational value of similarity or in terms of a reinforcement orientation emphasizing the affective value of similarity (Byrne \& Lamberth, 1971). The preponderance of the evidence favors the reinforcement view (Byrne, 1971), but the issue is far from settled. The present experiment was designed to test the relative merits of a reinforcement vs a cognitive balance explanation of the similarity-attraction relation.

As noted above, most of the evidence supports the view that similarity creates a state of affective arousal that is conditioned to evaluative (attraction) responses. However, there is considerable evidence (reviewed in Moss, Byrne, Baskett, \& Sachs, 1972) for a relation between attraction and assumed similarity. This evidence suggests that similarity may also serve as an informational determinant of attraction and, more generally, this evidence suggests the viability of a balance theory (Heider, 1958; Newcomb, 1956) in which similarity and attraction are viewed as two cognitive elements that tend toward balance.

Moss, Byrne, Baskett, and Sachs (1972) found that the similarity-attraction relation can to some extent be established in a reverse order. Ss provided with an attraction response could partially reproduce the pattern

\footnotetext{
*Requests for reprints should be sent to Clyde Hendrick, Department of Psychology, Kent State University, Kent. Ohio 44242.
}

of attitudes leading to such a response. The authors concluded that both affective and informational components contribute to the attraction process. Geen and Stonner (1970) manipulated Ss to have positive or negative conditioned affect for an individual's name, then exposed the Ss to one of three levels of opinion similarity relative to that individual. Opinion similarity interacted with conditioned affect in determining attraction, and the authors interpreted their results in terms of balance theory.

It would seem that awareness of similarity is a crucial variable for a balance approach to attraction. To the extent that similarity is salient in awareness, stronger pressures toward balance should exist, and a stronger similarity-attraction relation should be obtained. Actually, not much research has been done on the role of awareness of similarity in mediating attraction. Perceived similarity has typically not been measured in experiments conducted within the Byrne (1971) paradigm. However, one experiment by Byrne and Griffitt (1969) bears on the issue. It was found that for two measures of awareness of similarity, as actual similarity increased, perceived similarity also increased. It was found that verbalized similarity was related to attraction, although the correlation was low. It was concluded that awareness of similarity may contribute to the actual similarity-attraction relation but is not a necessary determinant

One difficulty with previous research is that no attempt has been made to manipulate degree or salience of awareness of similarity. Such an attempt was made in the present experiment. Ss examined the attitude response of five stimulus strangers, varying in proportion of attitudes similar to the Ss' attitudes, and rated their attraction toward each stranger. Half of the Ss rated perceived similarity to the five strangers prior to making 
the attraction ratings. and the other half made similarity ratings after the attraction ratings. If salience of similarity is a crucial variable, then the prior similarity ratings should create balance pressures that should result in a steeper function for actual similarity-attraction than for Ss not making prior similarity ratings. Thus, balance theory would predict an interaction between degree of actual similarity and salience of similarity in determining attraction. The reinforcement approach would not predict such an interaction because, as Byrne (1971, p. 175) suggested. "...a relatively automatic mechanism whereby the affective response to the stimulus person is determined by the series of cues associated with that person. Perceived similarity does not serve as a primary mediating factor but is simply another response variable which is in part determined by the external stimulus conditions."

One further problem requires comment. If the data came out favoring the balance interpretation, a critic might claim that the results were due to demand characteristics. This possibility was considered and discounted. Lamberth and Byme (1971) reported three experiments in which attempts were made to manipulate demand characteristics in a variety of ways. These attempts failed, and the only result was the usual robust similarity-attraction relation. Apparently this relationship is relatively impervious to laboratory demand characteristics.

\section{METHOD}

\section{Overview}

Students from an introductory psychology course served in groups of 10 to 45 in two sessions on 2 consecutive days. The experiment was represented as a study in interpersonal judgment. During the first session, Ss rated themselves on a 12-item self-attitude scale. During the second session, they rated their attraction and perceived similarity to five stimulus strangers who varied widely in actual similarity of self-attitudes to the Ss. Half of the Ss first rated their attraction for all five strangers. then rated perceived similarity to the five strangers. The other half completed the ratings in the reverse order.

\section{Stimulus Materials}

The initial attitude scale consisted of 12 forced-choice items. As an example, the two alternatives for the first item were: (a) I get so angry that $I$ feel like throwing and breaking things, and (b) I like to avoid responsibilities and obligations. All of the statements were moderately negative. For each of the 12 items, Ss circled one of the alternatives that applied best as a self-description. The descriptive content varied widely across the 12 items.

After the first session, five stimulus strangers were created for each $S$ based on the $S$ 's response pattern. The strangers were similar to the $S$ on $0,3,6,9$, or 12 items, representing proportions of $.00, .25, .50, .75$, or 1.00 actual similarity in self-attitudes. The attitude scales for the five strangers were stapled to form a booklet. Rating forms (either attraction or similarity) were interspersed between the strangers' attitude forms. The order of presentation of the five strangers was randomized within each booklet.

\section{Procedure}

When Ss arrived for the first session of the experiment. they were told: "This is an experiment in interpersonal judgment. We are interested in how you respond to people, given a limited amount of information about them. There are two parts to this experiment. During the first part, the part you are participating in today. I will want you to fill out a personality questionnaire about yourselves. This is to give us a measure of your personality traits. and to give you some idea of what the questionnaire is like. During the second part of the experiment, the part you will be participating in tomorrow, you will be given an opportunity to look over the questionnaires of five other people and answer questions about them."

The questionnaires were distributed in manila envelopes on which Ss recorded their name and sex. Instructions for completing the questionnaire were given and Ss made their self-ratings. When $S$ s arrived the next day for the second session. they received their manila envelope with a booklet of attitude forms purportedly completed by five strangers. Ss were asked to read over the attitude scale for each stranger and then rate the stranger on the scale following the attitude form. Each stranger was rated in the order presented. For half of the Ss, the rating form consisted of several questions assessing attraction toward the stranger. For the other half, the rating form consisted of several questions assessing perceived similarity.

When all the $S_{s}$ had completed the first questionnaire, they were then asked to complete a second questionnaire. This second set of forms assessed either attraction or perceived similarity for each stranger, depending on which rating condition the $S$ was in for the first set of ratings. Finally, after these ratings were completed. a copy of the initial attitude questionnaire was distributed, and Ss were asked to fill it out in the same way they had in the first session. The emphasis was on recall. Ss who could not recall how they initially answered at least 11 out of the 12 forced-choice questions were replaced. There were 22 such Ss.

\section{Rating Forms}

The similarity rating form included five questions. One item asked Ss to rate on a scale of 0-12 how many' items they and the stimulus person agreed upon in the attitude scale. The other four items asked for ratings of perceived similarity in personality. interests. values. and probable attitude similarity in a bull session. Each of these items was rated on a 9-point scale with endpoints appropriately labeled. Previous research, as well as data from the present study, showed that the latter four items were highly intercorrelated. Therefore, the four items were averaged to form a single index for perceived similarity.

The attraction rating form included eight questions, and each was rated on a 9-point scale. The items were liking. interesting to talk to, satisfying as a friend. enjoyable company, admirable. approximation to ideal, admirable qualities, and approval of the other person. These eight items were highly intercorrelated and. therefore, they were averaged to form a single attraction index.

\section{Subjects and Design}

There were 110 students who served as Ss. There was a roughly equal proportion of both seses. There was one between-S variable consisting of the order in which the ratings were made, either attraction/then similarity or similarity/then attraction. Fifty-five Ss were assigned randomly to each of these two conditions. Since each $S$ rated five strangers, stimulus strangers constituted a within-S variable. Thus, the full design was a 2 by 5 factorial, with one between and one within variable.

\section{RESULTS AND DISCUSSION}

The mean ratings for number of similar attitudes, 
Table 1

Mean Ratings for Number of Similar Items, Perceived Similarity, and Attraction

\begin{tabular}{|c|c|c|c|c|c|c|}
\hline \multirow[b]{2}{*}{ Variable } & \multirow[b]{2}{*}{ Order of Ratings } & \multicolumn{5}{|c|}{ Proportion of Similar Attitudes } \\
\hline & & .00 & .25 & .50 & .75 & 1.00 \\
\hline $\begin{array}{l}\text { 1. Number of Items } \\
\text { Perceived as Similar }\end{array}$ & $\begin{array}{l}\text { Similarity-Liking } \\
\text { Liking-Similarity }\end{array}$ & $\begin{array}{l}1.5 \\
1.3\end{array}$ & $\begin{array}{l}3.9 \\
3.9\end{array}$ & $\begin{array}{l}5.9 \\
5.7\end{array}$ & $\begin{array}{l}8.5 \\
8.2\end{array}$ & $\begin{array}{l}11.5 \\
11.0\end{array}$ \\
\hline $\begin{array}{l}\text { 2. Perceived } \\
\text { Similarity }\end{array}$ & $\begin{array}{l}\text { Similarity-Liking } \\
\text { Liking-Similarity }\end{array}$ & $\begin{array}{l}2.4 \\
2.3\end{array}$ & $\begin{array}{l}3.2 \\
3.5\end{array}$ & $\begin{array}{l}4.5 \\
4.8\end{array}$ & $\begin{array}{l}6.0 \\
6.4\end{array}$ & $\begin{array}{l}8.0 \\
7.9\end{array}$ \\
\hline 3. Attraction & $\begin{array}{l}\text { Similarity-Liking } \\
\text { Liking-Similarity }\end{array}$ & $\begin{array}{l}3.1 \\
3.4\end{array}$ & $\begin{array}{l}4.2 \\
4.0\end{array}$ & $\begin{array}{l}5.1 \\
5.2\end{array}$ & $\begin{array}{l}6.2 \\
6.2\end{array}$ & $\begin{array}{l}7.5 \\
7.3\end{array}$ \\
\hline
\end{tabular}

perceived similarity, and attraction are shown in Table 1. The ratings for number of similar attitudes indicates that Ss were quite accurate in their guesses. There was some slight restriction at the extremes $(.00$ and 1.00 similarity), but overall the guesses were quite accurate. The only significant effect was proportion of similar attitudes $(F=829.6, \quad \mathrm{df}=4 / 432, \quad \mathrm{p}<.0001)$. The interaction did not approach significance $(\mathrm{F}<1)$.

The measure of perceived similarity (average of four questions) was also very sensitive to the manipulation of proportion of similar attitudes. For the rating order of similarity/then liking, the means ranged from 2.4 for the .00 similar stranger to 8.0 for the 1.00 similar stranger. The comparable ratings for the liking/then similarity order were 2.3 and 7.9. The only significant effect was proportion of similar attitudes $(F=431.0, d f=4 / 432$, $\mathrm{p}<.0001)$. The interaciion was far from significance $(F=1.39)$.

The attraction ratings (average of eight questions) were comparable to the ratings of perceived similarity. The only significant effect was proportion of similar attitudes $(F=200.2, \quad d f=4 / 432, \quad p<.0001)$. The interaction was far from significance $(F=1.02)$.

The results offered no support for a balance theory of attraction. Instead, strong support was obtained for a reinforcement theory. In view of the lack of a significant interaction in any of the analyses of variance, further correlational analyses were performed. Byrne (1971) suggested that both perceived similarity and attraction are best viewed as two different dependent measures. determined in part by actual similarity. If this view is correct. then a factor analysis of all the rating data should show that perceived similarity and attraction tend to load on different factors.

This possibility was tested by two different factor analyses. In the first analysis, each $\mathrm{S}$ was considered as contributing 65 measures (13 for each stimulus stranger. including 5 similarity and 8 attraction measures for each stranger). The 65 measures were intercorrelated across all $110 \mathrm{Ss}$ and factored by the principal components method. Thirteen factors were extracted. Three factors were not meaningful. However, the other 10 factors were extremely clear. Five factors had high loadings for the similaity items for each of the five stimulus strangers. The other five factors had high loadings for the attraction items for each of the five stimulus strangers. Very clearly, perceived similarity and attraction measures loaded on different factors.

In the second type of analysis, stimulus strangers were ignored. Each $\mathrm{S}$ was treated as if he were five Ss, each of whom contributed 13 measures. In addition, number of similar attitudes was also treated as a variable. These 14 variables were intercorrelated and factored by the principal components method. A separate analysis was conducted for each of the two ratings orders (similarity-liking and liking-similarity). For each analysis, two factors were obtained. The factor loadings are shown in Table 2 . Inspection of the loadings indicates that for each analysis the first factor was an attraction factor. All of the attraction items loaded .76 or higher, while the highest loading for a similarity item was .55 . In contrast. Factor II had loadings of -.73 or higher for the similarity items, but the highest loading on this factor for an attraction item was - .50 . For each analysis, the first factor clearly tapped attraction and the second factor tapped similarity. In the first analysis, the two factors accounted for $87 \%$ of the total variance and. in the second analysis, the two factors accounted for $84 \%$

Table 2

Factor Analyses of the Rating Items

\begin{tabular}{|c|c|c|c|c|}
\hline \multirow[b]{3}{*}{ Variable } & \multirow{2}{*}{\multicolumn{2}{|c|}{$\begin{array}{c}\text { Analysis I } \\
\text { Liking/Then } \\
\text { Similarity } \\
\text { Condition } \\
\text { Factor }\end{array}$}} & \multirow{2}{*}{\multicolumn{2}{|c|}{$\begin{array}{l}\text { Analysis II } \\
\text { Similarity } \\
\text { Then Liking } \\
\text { Condition } \\
\text { Factor }\end{array}$}} \\
\hline & & & & \\
\hline & I & II & I & II \\
\hline Actual Similarity & .38 & -.84 & .52 & -.73 \\
\hline Perceived Similarity & .42 & -.87 & .54 & -.77 \\
\hline $\mathrm{PS}_{1}$ & .49 & -.83 & .48 & -.83 \\
\hline $\mathrm{PS}_{2}$ & .55 & -.78 & .47 & -.81 \\
\hline $\mathrm{PS}_{3}$ & .51 & -.80 & .48 & -.81 \\
\hline $\mathrm{PS}_{4}$ & .50 & -.81 & .51 & -.80 \\
\hline $\mathrm{Att}_{1}$ & .85 & -.39 & .76 & -.50 \\
\hline $\mathrm{Att}_{2}$ & .81 & -.27 & .85 & -.21 \\
\hline $\mathrm{Att}_{3}$ & .85 & -.35 & .79 & -.45 \\
\hline $\mathrm{Att}_{4}$ & .86 & -.38 & .79 & -.46 \\
\hline $\mathrm{Att}_{5}$ & .85 & -.37 & .80 & -.42 \\
\hline $\mathrm{Att}_{6}$ & .82 & -.43 & .81 & -.40 \\
\hline $\mathrm{Att}_{7}$ & .85 & -.40 & .81 & -.41 \\
\hline $\mathrm{Att}_{\mathrm{s}}$ & .85 & -.32 & .84 & -.33 \\
\hline
\end{tabular}

Note-Linder the lariable column. PS indicates a perceived similarity rating item and. At indicates an attraction rating itcm. 
of the total variance. It is of interest to note that in each analysis actual similarity loaded more highly on the similarity than on the attraction factor. Apparently. actual similarity determines perceived similarity more completely than it determines at traction. ${ }^{1}$

One possible difficulty with the present data concerns the effectiveness of the manipulations. Since no interactions occurred. one might question whether awareness of similarity was differentially manipulated. To explore this issue, the rating data for attraction and perceived similarity were each subjected to a trend analysis. For attraction the only result was a significant linear trend $(F=490.9 . d f=1 / 108, p<.0001)$, and none of the other components approached significance. For perceived similarity there was a significant linear component $(F=1079.8 . \quad \mathrm{df}=1 / 108 . \quad \mathrm{p}<.0001)$. However. there was also a significant quadratic component $(\mathrm{F}=22.7, \mathrm{df}=1 / 108, \mathrm{p}<.0001)$. More importantly for the issue at hand, there was a significant interaction of Quadratic Trend by Experimental Conditions $(F=5.8 . \mathrm{df}=1 / 108, \mathrm{p}<.02)$. A simple effects analysis for each experimental condition indicated that the quadratic component was significant for the similarity-liking condition $(F=26.2, p<.0001)$ but not for the liking-similarity condition $(F=2.57)$. When Ss first rated similarity to stimulus persons, the pattern of the five means contained significant quadratic curvature (as well as a linear trend), but, when similarity ratings were made after the attraction ratings, there was only a significant linear trend. These trend differences strongly suggest that similarity awareness was differentially manipulated.

The analyses overall generally supported the reinforcement view of attraction. The lack of an interaction between proportion of similar attitudes and order of ratings in determining attraction suggests that any pressures toward balance, if they exist, are slight. The two orthogonal factors for attraction and similarity in the factor analyses also suggest that perceived similarity and attraction do not tend toward balance arrangements and support Byme's (1971. p. 175) suggestion that perceived similarity and attraction are two separate dependent variables, each partially determined by the stimulus arrangements of objective similarity.

There were subtle nuances in the data, however, that suggest an interesting pattern of interdependence. The correlations noted in Note 1 suggest that actual similarity affected perceived similarity: which in turn affected attraction. Another interpretation is that actual similarity influenced attraction, which then influenced perceived similarity. The results for the trend analyses support this reasoning. Once Ss knew how much they liked the stimulus persons, their perceived similarity ratings aligned themselves in perfect linear order. This was not true when similarity was assessed before liking, because there was significant curvature in the similarity ratings in this condition. although not in the attraction ratings. As noted earlier. there is evidence for a strong relation between attraction and assumed similarity. Thus. the present analysis suggests that one's perception of how much he likes someone will affect his perception of similarity more strongly than initial perception of similarity will affect attraction. This analysis suggests that perceived similarity is to some extent a dependent variable, determined partially by perceived attraction. This approach does not deny the efficacy of the reinforcement model. of course, but it does suggest that in a very restricted sense a balance model might still be applicable.

\section{REFERENCES}

Byme. D. The attraction paradigm. New York: Academic Press. 1971.

Byme, D.. \& Griffitt. W. Similarity and awareness of similarity of personality characteristics as determinants of attraction. Journal of Experimental Research in Personality. 1969. 3. 179-186.

Byrne. D.. \& Lamberth. J. Cognitive and reinforcement theories as complementary approaches to the study of attraction. In B. 1. Murstein (Ed.). Theories of attraction and lore. New Jork: Springer. 1971.

Geen. R. G.. \& Stonner. D. The relationship of belief similarity to attraction following conditioning and generalization of affect. Paper presented at the annual convention of the Midwestern Psychological Association. Detroit. Michigan. May 1970.

Heider. F. The pslchology of interpersonal relations. lew York: Wiley, 1958

Hendrick. C.. \& Brown. S. R. Introversion. extraversion, and interpersonal attraction. Journal of Personality \& Social Psichology. 1971. 20, 31-36.

Lamberth. J., \& Bỵne. D. Similarity-attraction or demand characteristics? Personality: An International Journal. 1971 2. $77-91$

Moss. M. K.. Byrne, D.. Baskett. G. D., \& Sachs. D. H Informational versus affective determinants of interpersonal attraction. Lnpublished manuscript. Purdue Lniversity. 1972.

Newcomb, T. M. The prediction of interpersonal attraction. American Psychologist. 1956. 11. 575-586.

\section{NOTE}

1. It should be noted that. although similarity and attraction separated as orthogonal factors in the factor analyses. the intercorrelations between actual similarity. perceived similarity (averaged across four items). and attraction (averaged across eight items) were quite high. as might be expected. The correlations between actual and perceived similarity were .82 and .85 for the similarity-liking and liking-similarity conditions. respectively. The comparable correlations for actual similarity and attraction were somewhat lower. .79 and .69. respectively. The correlations between perceived similarity and attraction were .83 and .81 . respectively. These correlations support the results of the factor analyses. but they do suggest that perceived similarity is related to attraction to a greater extent than is indicated by the factor analyses.

Received for publication January 13.1973; revision received May 9. 1973.) 